\title{
EDUCAÇÃO COMO PRÁTICA DA LIBERDADE
}

\section{EDUCATION AS A PRACTICE OF FREEDOM}

\section{LA EDUCACIÓN COMO PRÁCTICA DE LA LIBERTAD}

\section{Cristina Bárbara Martins Teixeira ${ }^{1}$ \\ https://orcid.org/0000-0002-0200-2275}

${ }^{1}$ Instituto Federal de Educação, Ciência e Tecnologia do Triângulo Mineiro, Uberaba - MG, cristina.bm.fp@gmail.com,

Educação como prática da liberdade foi escrito em 1967 durante o exílio de Paulo Freire no Chile, contém 150 páginas e foi publicado pela editora Paz e Terra. Essa obra tem indiscutível importância histórica, tanto política, quanto pedagogicamente, tendo em vista sua repercussão em tantas edições. Nesse livro o autor expõe o seu método de alfabetização de adultos de maneira minuciosa, contextualizando historicamente a proposta e expondo seus pressupostos filosóficos e políticos, dizendo sobre uma educação que liberta seres humanos da condição de oprimidos e inserindo-os na sociedade como forças transformadoras, críticas, politizadas e responsáveis por todas as pessoas que a integram.

Além da apresentação de Francisco C. Weffort - Educação e Política - e do prefáciopoema de Thiago de Mello - Canção Para os Fonemas de Alegria -, essa edição reúne apêndice com exemplos de situações existenciais que possibilitam, no Método, a apreensão do conceito de cultura, sendo acompanhadas de desenhos de Vicente de Abreu feitos a partir das pinturas originais de Francisco Brennand.

A obra é dividida em quatro capítulos: "A Sociedade Brasileira em Transição" - o autor apresenta sua interpretação a respeito das forças políticas que disputavam o poder no início da década de 1960; "Sociedade Fechada e Inexperiência Democrática" - Paulo Freire resgata momentos da história do Brasil; "Educação Versus Massificação" - o autor explica sua concepção pedagógica; "Educação e Conscientização" - Freire mostra as experiências pedagógicas do Método de Alfabetização de Adultos ocorridas no Brasil no período pré-64.

Para melhor compreensão do leitor, esta resenha pretendeu expor o que considera essencial em cada capítulo, conservando cuidadosamente os fundamentos filosóficos e políticos do autor. 
1. A Sociedade Brasileira em Transição - Paulo Freire apresenta sua interpretação a respeito das forças políticas do início da década de 1960, pontuando que tal época era um momento de transição e que é nesses momentos que o homem tem a possibilidade de fazer mudança em seu papel, podendo deixar de ser objeto para ser sujeito. Para Freire, as relações que o homem trava no mundo e com o mundo possuem diversas características que as diferenciam das relações dos demais animais. Entre elas, as conotações de pluralidade, de criticidade, de transcendência, de consequência e de temporalidade.

De acordo com Freire, o homem em suas relações, criando e recriando, integrando-se às condições de seu contexto, respondendo a seus desafios, objetivando-se a si próprio, discernindo, transcendendo, lança-se num domínio que lhe é exclusivo, o da História e o da Cultura. A integração do homem ao seu contexto o enraíza e o torna um ser situado e datado. Para Freire, a grande luta dos homens seria a de superar os fatores que o faziam acomodado ou ajustado, era a luta por sua humanização, ameaçada constantemente pela opressão que o esmagava.

Freire demonstra que a humanização ou desumanização do homem e sua afirmação como sujeito ou sua minimização como objeto dependeriam da captação ou não de sua realidade histórica, já que, somente se preparando para essa captação, é que poderia interferir, em vez de ser simples espectador.

O Brasil vivia a passagem de uma época para outra. O ponto de partida do trânsito seria de uma sociedade "fechada", que era alienada, objeto, e não sujeito de si mesma. Essa sociedade rachou-se, a rachadura decorreu da ruptura nas forças que mantinham a sociedade fechada em equilíbrio. Para Freire, se ainda não era uma sociedade aberta, já não era, contudo, uma sociedade totalmente fechada; parecia ser uma sociedade abrindo-se, com preponderância de abertura nos centros urbanos e de fechamento nos rurais, correndo o risco, pelos possíveis recuos no trânsito, como o Golpe de Estado, de um retorno catastrófico ao fechamento. Para Freire, a salvação democrática estaria em fazer uma sociedade homogeneamente aberta.

Para o autor, o novo clima cultural começava a se formar, a sociedade ganhava, pouco a pouco, a consciência de suas possibilidades como resultado imediato de sua inserção no seu mundo e da captação das tarefas de seu tempo ou da visão nova dos velhos temas. Começavam a fazer-se críticos e, por isso, renunciavam tanto ao otimismo ingênuo e aos idealismos utópicos quanto ao pessimismo e à desesperança e se tornavam criticamente otimistas. 
À medida que iam se integrando com seu tempo e seu espaço, a posição anterior de inferioridade, característica da alienação, começava a ser substituída por uma outra, de alta confiança. A sociedade passava, assim, a se conhecer, renunciando à velha postura de objeto e assumindo a de sujeito. Isso implicava uma crescente participação do povo no seu processo histórico. E essa participação, que implicava uma tomada de consciência, e não ainda uma conscientização, ameaçava as elites detentoras de privilégios, levando-as a reagirem, criando instituições assistenciais.

Segundo Freire, o perigo do assistencialismo estava na violência do seu antidiálogo, que, impondo ao homem mutismo e passividade, não lhe oferecia condições especiais para o desenvolvimento ou a abertura de sua consciência, que, nas democracias autênticas, haveria de ser cada vez mais crítica.

Para o autor, não seria com soluções dessa ordem assistencialista que se ofereceria ao país uma destinação democrática, mas, sim, a partir de uma educação corajosa, propondo ao povo a reflexão sobre si mesmo, sobre seu tempo, sobre suas responsabilidades, sobre seu papel no novo clima cultural da época de transição. Na fase de transição brasileira, entretanto, à medida que o clima emocional se intensificava e o racionalismo sectário, sobretudo de direita, se fortalecia, fazia-se cada vez mais difícil uma educação capaz de corresponder a esse fundamental desafio. Consolidavam-se as barreiras contra essa educação.

2. Sociedade Fechada e Inexperiência Democrática - Paulo Freire resgata momentos da história do Brasil, pontuando que a sociedade "fechada" brasileira era consequência da colonização e existia uma inexperiência democrática, que era uma das marcas mais fortes do país. Para Freire, isso ocorreu pelo fato de a colonização brasileira ter sido uma empreitada comercial, na qual os colonizadores não tinham a intenção de criar uma civilização. Sendo assim, essa colonização demonstrava distância social e não permitia dialogação.

Para Freire, a dialogação implicava a responsabilidade social e política do homem, implicava o mínimo de consciência transitiva, que não se desenvolvia nas condições oferecidas pelo grande domínio. Freire demonstra que a característica da formação da sociedade brasileira foi o poder exacerbado a que foi se associando sempre a submissão, originando ajustamento e acomodação.

No ajustamento, o homem não dialoga, não participa, acomoda-se a determinações que se superpõem a ele. Com essa política de colonização, não era possível ter experiências democráticas e, em todo o período de vida colonial, os brasileiros foram proibidos de falar. Freire destaca a ocorrência de rachaduras na sociedade brasileira, como, por exemplo, quando 
a Corte se instalou no Rio de Janeiro; mas segundo ele, os brasileiros continuaram a alimentar a inexperiência democrática como uma experiência caracterizada por uma mentalidade feudal.

De acordo com Freire, não havia onde buscar condições de que tivesse emergido uma consciência popular democrática, permeável e crítica sobre a qual se podia fundar autenticamente o mecanismo do estado democrático devido ao tipo de colonização. Uma ação democrática em geral teria que ser feita não só com o consentimento do povo, mas com suas próprias mãos. Freire alude que o povo assistiu à proclamação da República bestificado, porém, no caso do Golpe Militar, já não tanto bestificado. A população estava começando a entender que era sua crescente participação nos acontecimentos políticos brasileiros que assustava as forças, quebrando o equilíbrio que mantinha a sociedade fechada, provocando uma rachadura na sociedade, que entra então na fase de transição.

3. Educação Versus Massificação - O autor explica sua concepção pedagógica elucidando que, a partir de suas análises, preocupava-se em encontrar uma resposta no campo da pedagogia às condições da fase de transição brasileira, que deveria ser pautada em uma educação crítica e criticizadora. Ao retratar as condições da fase de transição brasileira e as características presentes na educação daquela época, Freire demonstra que as minorias estavam excluídas da órbita das decisões, comandadas pelos meios de publicidade a tal ponto, que em nada confiavam ou acreditavam se não tivessem ouvido no rádio ou na televisão.

Para Freire, a educação estava cada vez mais em posições ingênuas, deixando a população na periferia de tudo o que era tratado, quase sempre levando-a à passividade, ao conhecimento memorizado apenas, não exigindo dela elaboração ou reelaboração, deixando-a em posição de inautêntica sabedoria. Essa cultura fixada na palavra, segundo Freire, correspondia à inexperiência do diálogo, o qual estava intimamente ligado à criticidade, nota fundamental da mentalidade democrática. Então, não seria possível, com uma educação assim, formar homens que se integrassem a esse impulso de democratização, já que essa educação contradizia esse impulso e enfatizava a inexperiência democrática.

De acordo com o autor, a democracia estava em aprendizagem, fortemente marcada por descompassos nascidos da inexperiência do autogoverno, ameaçada pelo risco de não ultrapassar a transitividade ingênua. Freire, no entanto, pontua que o Brasil estava vivendo uma fase de influências "renovadoras" por intermédio do rádio, do cinema e da televisão, fase em que a transitividade da consciência se associava ao fenômeno da rebelião popular, e essa rebelião era um sintoma de ascensão, como uma introdução à plenitude, mas que não poderia ficar só nas suas manifestações preponderantemente passionais. Era necessário um senso de responsabilidade, de criticidade.

Educação: Teoria e Prática/ Rio Claro, SP/ v. 31, n.64/2021. eISSN 1981-8106 e36[2021] 
Para isso, o homem brasileiro teria de ganhar a sua responsabilidade social e política. Para essa responsabilidade existir, era necessária a participação, para a qual havia a necessidade de uma educação que tentasse a passagem da transitividade ingênua à transitividade crítica, ampliando e alargando a capacidade de captar os desafios do tempo, colocar o homem brasileiro em condições de resistir aos poderes da emocionalidade da própria transição.

Para Freire, o grande desafio nas novas condições da vida brasileira não era só o alarmante índice de analfabetismo e a sua superação - o problema prosseguia e transcendia a superação do analfabetismo e se situava na necessidade de superar, também, a inexperiência democrática.

4. Educação e Conscientização - Paulo Freire mostra o seu projeto de educação para os adultos, confirmando a necessidade de olhar para os déficits quantitativos e qualitativos da educação. Esse projeto se dava mediante os Círculos de Cultura, nos quais eram instituídos debates em grupos que estavam em busca do esclarecimento de situações. A programação desses debates era oferecida pelos próprios grupos por meio de entrevistas que eram mantidas com eles e de que resultava a enumeração de problemas que gostariam de debater.

Paulo Freire relata que a educação que ele propunha era totalmente afastada da alfabetização puramente mecânica. Pelo contrário, seria uma alfabetização de tomada de consciência, direta e ligada à democratização da cultura, que fosse, em si, um ato de criação, capaz de desencadear outros atos criadores. Mas como realizar essa educação? Para Freire, a resposta estava em um método ativo, dialogal, crítico e criticizador, na modificação do conteúdo programático da educação, no uso de técnicas como a da redução e codificação.

Para Freire, o diálogo era indispensável no caminho dessa nova formação e começaria pelo conceito antropológico de cultura; a cultura como resultado de seu trabalho, do seu esforço criador e recriador, o sentido transcendental de suas relações, a dimensão humanista da cultura, a democratização da cultura, o aprendizado da escrita e da leitura como uma chave com que o analfabeto iniciaria a sua introdução no mundo da comunicação escrita. A partir daí, o analfabeto começaria a operação de mudança de suas atitudes anteriores, descobrindose como fazedor desse mundo da cultura.

A conclusão dos debates girava em torno da dimensão da cultura como aquisição sistemática da experiência humana. Daí passava-se ao debate da democratização da cultura, com que se abriam as perspectivas para o início da alfabetização. Todo esse debate era criticizador e motivador. $\mathrm{O}$ analfabeto apreendia criticamente a necessidade de aprender a ler e a escrever. 
O método de Freire era dividido em algumas fases de elaboração e de execução prática. No momento da elaboração havia cinco fases. Primeira: levantamento do universo vocabular dos grupos com quem se trabalharia; segunda: escolha das palavras selecionadas do universo vocabular pesquisado; terceira: criação de situações existenciais típicas do grupo com quem se iria trabalhar; quarta: elaboração de fichas-roteiro que auxiliavam os coordenadores de debate no seu trabalho; quinta: elaboração de fichas com a decomposição das famílias fonéticas correspondentes aos vocábulos geradores.

Depois de confeccionado esse material, eram preparadas e treinadas as equipes de coordenadores e supervisores, que recebiam suas fichas-roteiro para, assim, iniciarem o trabalho. No momento da execução começava-se com a projeção da situação com a primeira palavra geradora, a representação gráfica da expressão oral da percepção do objeto e, depois, iniciava-se o debate em torno de suas implicações. Somente quando o grupo esgotava a análise da situação dada, voltava-se o educador para a visualização da palavra geradora (para a visualização, e não para sua memorização). Visualizada a palavra, estabelecido o vínculo semântico entre ela e o objeto a que se referia, representado na situação, apresentava-se ao educando, de outra forma, a palavra sem o objeto que a nomeava.

Logo após, apresentava-se a mesma palavra separada em sílabas, que o analfabeto, de modo geral, identificava como "pedaços". Reconhecidos os "pedaços", na etapa da análise, passava-se à visualização das famílias fonêmicas que compunham a palavra em estudo. Essas famílias, que eram estudadas isoladamente, passavam depois a ser apresentadas em conjunto, chegando-se à última análise, que levava ao reconhecimento das vogais.

A ficha que apresentava as famílias em conjunto foi chamada de ficha da descoberta. Por meio dela, fazendo a síntese, o aluno descobria o mecanismo de formação vocabular numa língua silábica, que se fazia por meio de combinações fonêmicas. Apropriando-se criticamente, e não memorizadamente, o que não seria uma apropriação, desse mecanismo, começava a produzir por si mesmo seu sistema de sinais gráficos. Começava, então, com maior facilidade, a criar palavras com as combinações fonêmicas à sua disposição que a decomposição de um vocábulo trissilábico lhe oferecia.

Terminados os exercícios orais, em que não houve apenas conhecimento, mas reconhecimento, sem o que não há verdadeira aprendizagem, o aluno passava, na mesma noite, a escrever. De acordo com Freire, na alfabetização de adultos, para que não seja puramente mecânica e memorizada, o que se devia fazer era proporcionar-lhes conscientização para que se alfabetizassem. Daí, à medida que o método ativo ajudava a pessoa a se conscientizar em torno de sua problemática, em torno de sua condição de pessoa, Educação: Teoria e Prática/ Rio Claro, SP/ v. 31, n.64/2021. eISSN 1981-8106 e36[2021] 
por isso de sujeito, ela se instrumentalizaria para as suas opções. Aí, então, ela mesma se politizaria.

Freire destaca que, se tivesse sido cumprido o programa elaborado no governo Goulart, em 1964, poderiam ter funcionado mais de 20.000 Círculos de Cultura em todo o país e haveria o levantamento da temática do homem brasileiro. Esses temas, submetidos à análise de especialistas, seriam reduzidos a unidades de aprendizado, à maneira como foi feito com o conceito de cultura e com as situações em torno das palavras geradoras. Esse levantamento teria possibilitado uma séria programação que se seguiria à etapa da alfabetização, mas, ainda, com a criação de um catálogo de temas reduzidos e referências bibliográficas que teria sido colocado a disposição dos colégios e universidades, ampliando o raio de ação da experiência e contribuindo para a indispensável identificação da escola com a realidade.

É indiscutível a importância de Paulo Freire para a educação no Brasil e em diversas partes do mundo. Sua obra é, ainda hoje, referência, o que justifica tantas edições. Com a leitura desse livro é possível entrar em contato com a filosofia e a pedagogia de Freire, além de conhecer o que o autor defendia: o papel do professor deveria ser o de possibilitar a criação e a produção de conhecimento; o papel da escola seria de ensinar os estudantes a ler o mundo; a educação é o meio para despertar a criticidade do aluno para que ele atinja sua autonomia; e a educação possibilitaria o desenvolvimento de uma percepção crítica quanto à desigualdade entres as classes sociais, que tem como consequência a opressão das classes populares.

Entre as contribuições do autor está a percepção de que cada estudante leva consigo a sua cultura para a sala de aula, e essa não deve ser considerada melhor nem pior que a do professor. Nesse sentido, o respeito à cultura do aluno se revelou como uma das maneiras de tornar a educação mais afetiva e democrática, considerando que todos são fontes de conhecimento. Na pedagogia freiriana, todos têm direito a se manifestar criticamente.

\section{Referências}

FREIRE, P. Educação como prática da liberdade. Rio de Janeiro: Paz e Terra, 1967.

FREIRE, P. (1921). Conscientização: teoria e prática da libertação: uma introdução ao pensamento de Paulo Freire. 3. ed. São Paulo: Moraes, 1980.

Recebido em: 16/10/2018

Revisado em: 08/09/2021

Aprovado em: 07/10/2021

Publicado em: 29/10/2021 